\title{
Can particulate matter be identified as the primary cause of the rapid spread of CoViD-19 in some areas of Northern Italy?
}

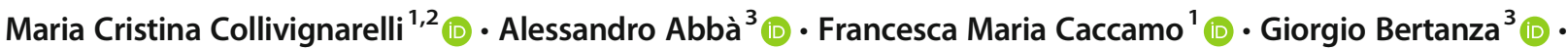 \\ Roberta Pedrazzani ${ }^{4}$ (D) Marco Baldi $^{5} \cdot$ Paola Ricciardi $^{1}$ (D) $\cdot$ Marco Carnevale Miino $^{1}$ (D)
}

Received: 27 July 2020 / Accepted: 26 January 2021 / Published online: 26 February 2021

(C) The Author(s) 2021

\begin{abstract}
Northern Italy was the most affected by CoViD-19 compared to other Italian areas and comprises zones where air pollutants concentration was higher than in the rest of Italy. The aim of the research is to determine if particulate matter (PM) has been the primary cause of the high CoViD-19 spread rapidity in some areas of Northern Italy. Data of PM for all the 41 studied cities were collected from the local environmental protection agencies. To compare air quality data with epidemiological data, a statistical analysis was conducted identifying the correlation matrices of Pearson and Spearman, considering also the possible incubation period of the disease. Moreover, a model for the evaluation of the epidemic risk, already proposed in literature, was used to evaluate a possible influence of PM on CoViD-19 spread rapidity. The results exclude that PM alone was the primary cause of the high CoVid-19 spread rapidity in some areas of Northern Italy. Further developments are necessary for a better comprehension of the influence of atmospheric pollution parameters on the rapidity of spread of the virus SARS-CoV-2, since a synergistic action with other factors (such as meteorological, socio-economic and cultural factors) could not be excluded by the present study.
\end{abstract}

Keywords $\mathrm{PM}_{10} \cdot \mathrm{PM}_{2.5} \cdot \mathrm{SARS}-\mathrm{CoV}-2 \cdot$ Doubling time $\cdot$ Coronavirus $\cdot$ Epidemic

\section{Introduction}

A strong correlation between air particulate pollution and the increase of autoimmune and respiratory diseases has been confirmed by several studies (Cruz-Sanchez et al. 2013; Horne et al. 2018; Tateo et al. 2019; Xu et al. 2016; Zhou et al. 2015). Moreover, recent studies highlighted a positive

Responsible editor: Philippe Garrigues

Marco Carnevale Miino

marco.carnevalemiino01@universitadipavia.it

1 Department of Civil Engineering and Architecture, University of Pavia, via Ferrata 3, 27100 Pavia, Italy

2 Interdepartmental Centre for Water Research, University of Pavia, via Ferrata 3, 27100 Pavia, Italy

3 Department of Civil, Environmental, Architectural Engineering and Mathematics, University of Brescia, via Branze 43,

25123 Brescia, Italy

4 Department of Mechanical and Industrial Engineering, University of Brescia, via Branze 38, 25123 Brescia, Italy

5 Department of Chemistry, University of Pavia, viale Taramelli 10, 27100 Pavia, Italy correlation between the mortality rate for CoViD-19 and longterm exposure to high concentrations of pollutants such as particulate matter (PM), $\mathrm{SO}_{2}, \mathrm{CO}, \mathrm{NO}_{2}$ and $\mathrm{O}_{3}$ (Coccia 2020; Ogen 2020; Coker et al. 2020; Wu et al. 2020a, 2020b; Perone 2021; Yari and Moshammer 2020). For instance, Cole et al. (2020) observed a link between long-term $\mathrm{PM}_{2.5}$ exposure and CoViD-19 cases, hospital admissions and deaths in 355 municipalities in the Netherlands. Moreover, Isphording and Pestel (2020) statistically analysed the proliferation and aggressiveness of CoViD-19 in Germany highlighting a strong correlation between short-term exposure to air pollution and severe clinical reactions. However, the air pollution may have influenced not only the aggressiveness of CoViD-19.

The Italian Society of Environmental Medicine (SIMA) (SIMA 2020) supposed for the first time a possible correlation between the significant spread of coronavirus disease (CoViD-19), caused by Severe Acute Respiratory Syndrome Coronavirus 2 (SARS-CoV-2) (Collivignarelli et al. 2020b), in Northern Italy and the high levels of $\mathrm{PM}_{10}$ and $\mathrm{PM}_{2.5}$. Setti et al. (2020a, 2020b) and several other authors supposed that PM could acts as a support for novel SARS coronavirus (SARS-CoV-2), allowing the spread and the transport even 


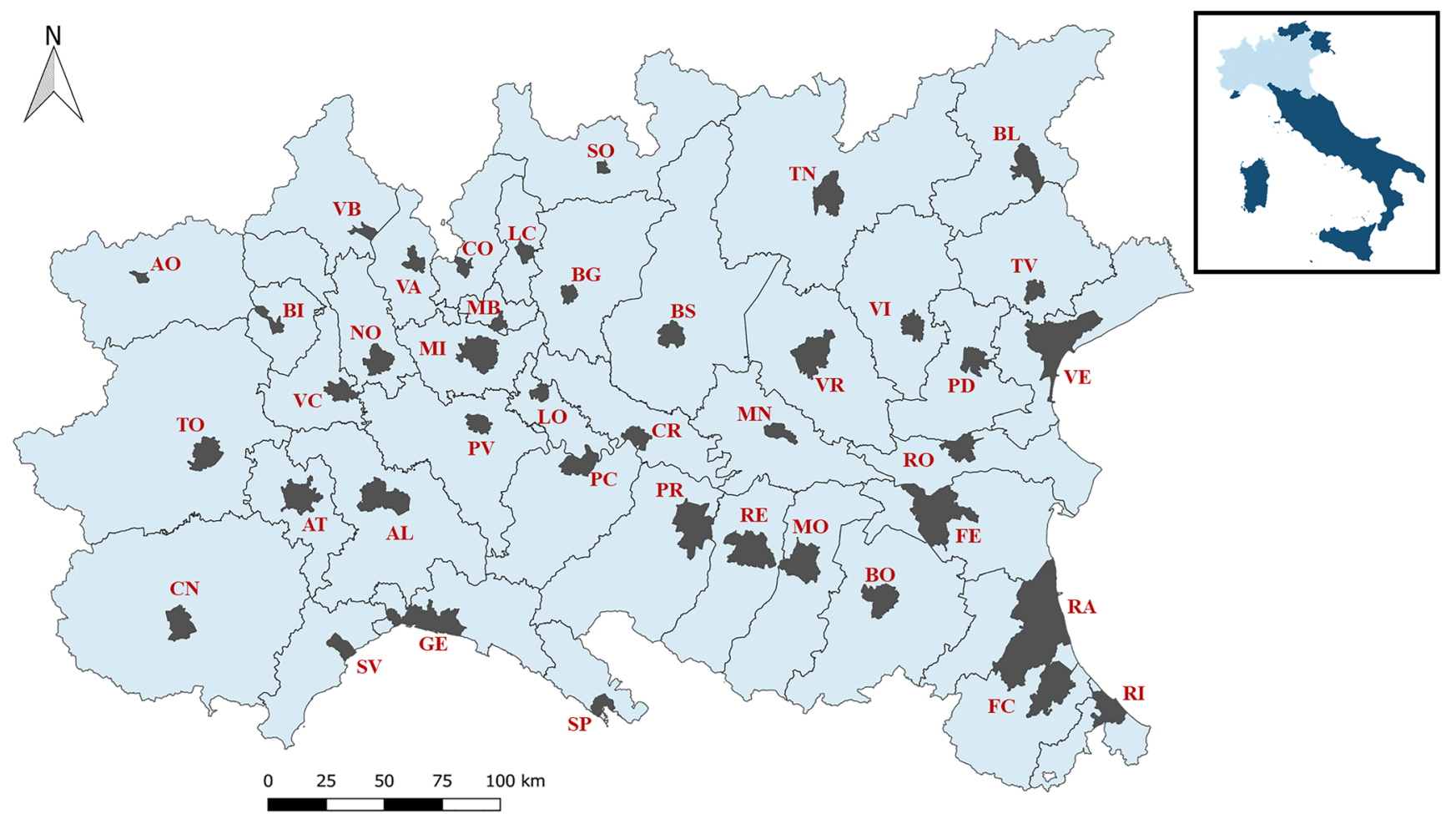

Fig. 1 Map of the area analysed in the study and its location in Italy. The capital city for each province is highlighted in grey. The map has been realised with QGIS (2020). AL: Alessandria; AO: Aosta; AT: Asti; BG: Bergamo; BI: Biella; BL: Belluno; BO: Bologna; BS: Brescia; CN: Cuneo; CO: Como; CR: Cremona; FC: Forlì and Cesena; FE: Ferrara; GE: Genoa; LC: Lecco; LO: Lodi; MB: Monza; MI: Milan; MN:

for significant distances. According to this thesis, PM could represent a substrate that allows the virus to remain in the air in a contagious form for hours or days, promoting its diffusion (Sanità di Toppi et al. 2020; SIMA 2020). On the contrary, Belosi et al. (2021) showed that the probability of transmission in the outdoor environment of SARS-CoV-2 is not subjected to a substantial increase even in the presence of a high concentration of PM. This would seem to deny the presence of a possible strong correlation between the high rapidity of CoViD-19 spread in some areas of northern Italy and atmospheric PM. Therefore, due to contrasting results observed, this aspect is still the subject of analysis and discussion by the scientific community.

To date, no studies evaluated whether $\mathrm{PM}_{10}$ and $\mathrm{PM}_{2.5}$ influence the diffusion rapidity of the virus (intended as doubling time and seeding time (DT and ST), respectively), playing or not a key role in the massive spread of CoViD19. This study aims to explore this relationship in Northern Italy, which has been the most affected area by CoViD-19 (INCP 2020), and is also the portion of the country presenting some areas with the highest amount of atmospheric PM often exceeding the legislative limit (Ionescu et al. 2013; Torretta et al. 2013; Masiol et al. 2015). Together with Poland and Bulgaria, Northern Italy has the worst air quality in Europe
Mantova; MO: Modena; NO: Novara; PC: Piacenza; PD: Padua; PR: Parma; PV: Pavia; RA: Ravenna; RE: Reggio Emilia; RI: Rimini; RO: Rovigo; SO: Sondrio; SP: La Spezia; SV: Savona; TN: Trento; TO: Turin; TV: Treviso; VA: Varese; VB: Verbania; VC: Vercelli; VE: Venice; VI: Vicenza; VR: Verona

in terms of PM (EEA 2019, 2018, 2017). Data of $\mathrm{PM}_{10}$ and $\mathrm{PM}_{2.5}$ were analysed and, considering an incubation time of $10-15 \mathrm{~d}$, were compared with the CoViD-19 rapidity of spread, evaluated using the ST and DT, in 41 cities of Northern Italy. In order to compare air quality data with epidemiological data, a statistical analysis was conducted and also the CoViD-19 ST/DT model proposed by Zhou et al. (2020) for the evaluation of the epidemic risk was used to investigate a possible correlation with PM.

\section{Methods}

\section{Area of the study}

Considering that CoViD-19 has broken out in Northern Italy, this part of the country has been selected in order to detect a possible correlation between epidemic spread and PM in air. According to the most recent available data, the area of the study was larger than $100,000 \mathrm{~km}^{2}$ (ISTAT 2020a) and divided in 41 provinces, in seven different Regions (Piedmont, Valle d'Aosta, Lombardy, Liguria, Veneto, Trentino and Emilia-Romagna) totally accounting for around 25.8 million of inhabitants (ISTAT 2020b). The analysis has been applied 


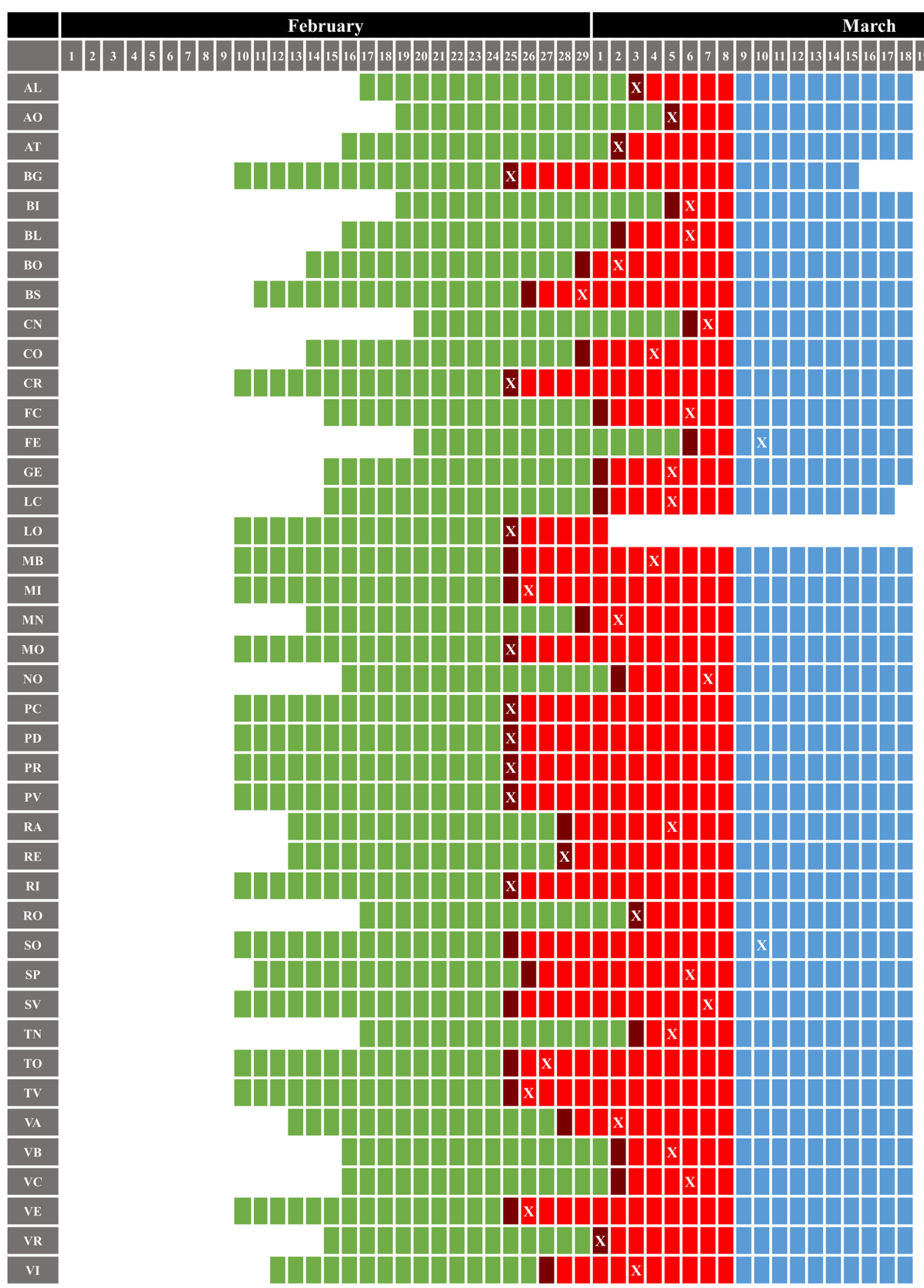

\section{Air quality data}

Fig. 2 Selected periods for air quality monitoring and epidemiological data collection. $\mathrm{T} 0$ represents the first case identified in each province and reported by official data and $\mathrm{T} 1$ the day before the rise of the epidemiological curve. For the determination of T0 and T1, please refer to "Epidemiological analysis". AL: Alessandria; AO: Aosta; AT: Asti; BG: Bergamo; BI: Biella; BL: Belluno; BO: Bologna; BS: Brescia; CN: Cuneo; CO: Como; CR: Cremona; FC: Forlì and Cesena; FE: Ferrara;

\section{$\begin{array}{llll}\text { Epidemiological data } & \text { T0 } & \mathrm{X} & \mathrm{T} 1\end{array}$}

GE: Genoa; LC: Lecco; LO: Lodi; MB: Monza; MI: Milan; MN: Mantova; MO: Modena; NO: Novara; PC: Piacenza; PD: Padua; PR: Parma; PV: Pavia; RA: Ravenna; RE: Reggio Emilia; RI: Rimini; RO: Rovigo; SO: Sondrio; SP: La Spezia; SV: Savona; TN: Trento; TO: Turin; TV: Treviso; VA: Varese; VB: Verbania; VC: Vercelli; VE: Venice; VI: Vicenza; VR: Verona 
ST
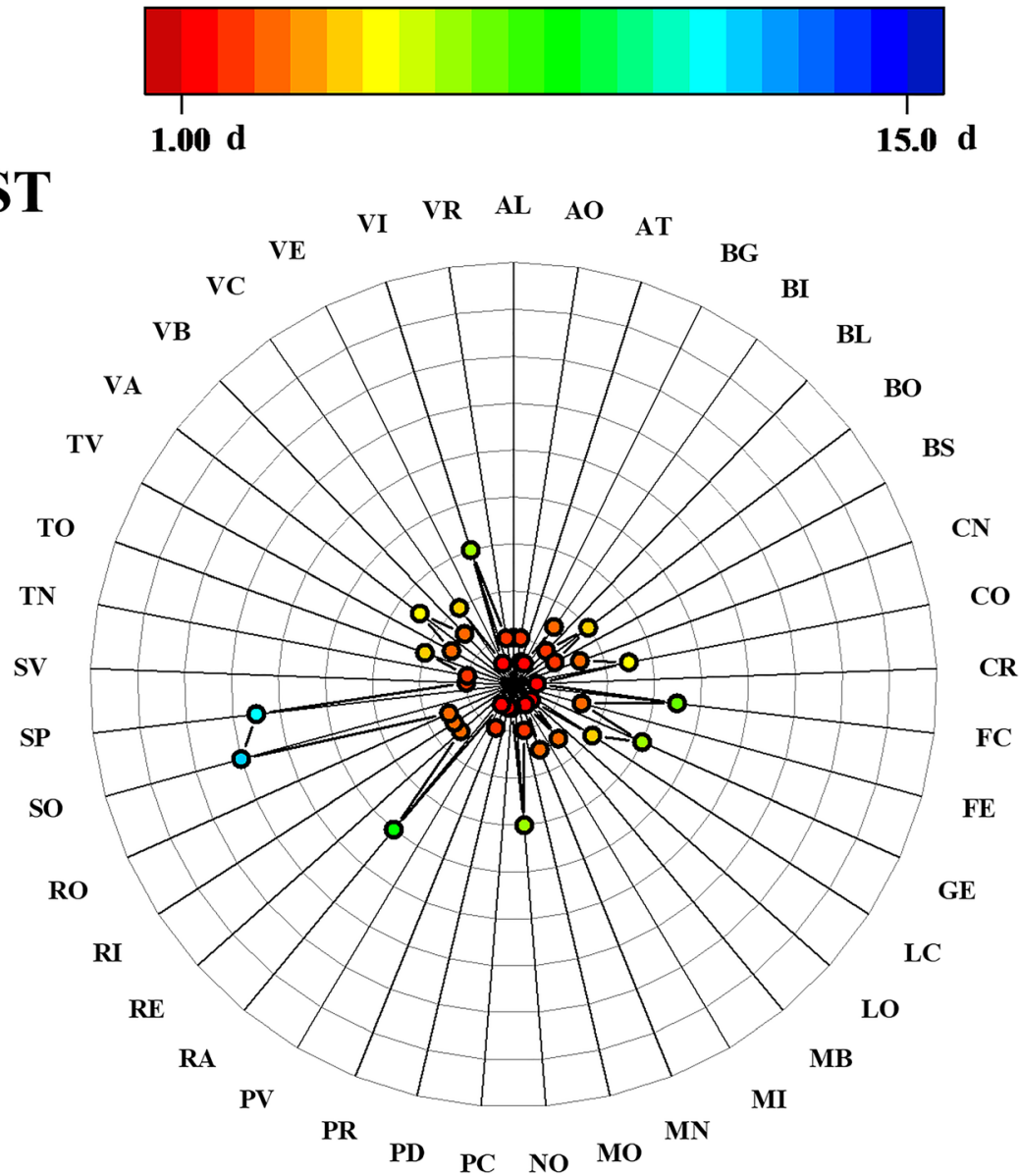

DT

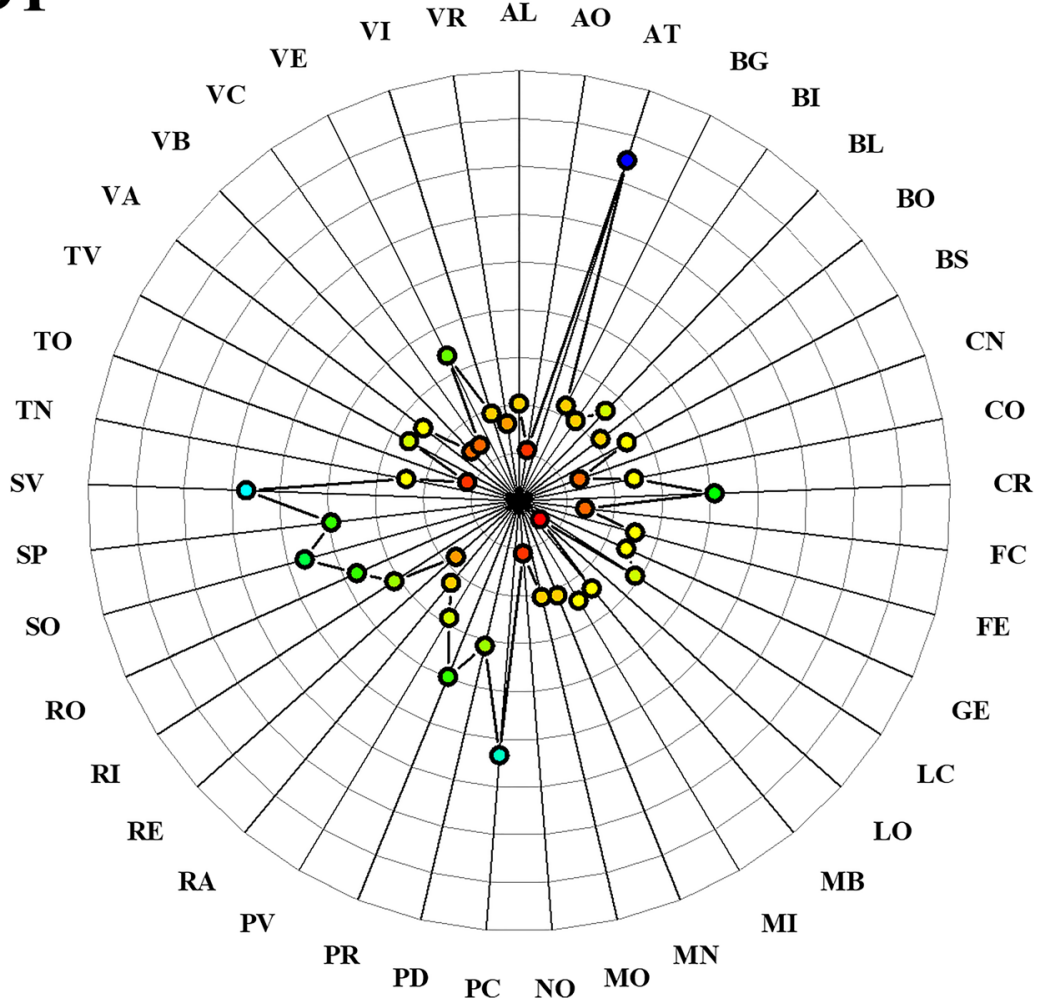


Fig. 3 Value of seeding time (ST) and doubling time (DT) for each city. AL: Alessandria; AO: Aosta; AT: Asti; BG: Bergamo; BI: Biella; BL: Belluno; BO: Bologna; BS: Brescia; CN: Cuneo; CO: Como; CR: Cremona; FC: Forlì and Cesena; FE: Ferrara; GE: Genoa; LC: Lecco; LO: Lodi; MB: Monza; MI: Milan; MN: Mantova; MO: Modena; NO: Novara; PC: Piacenza; PD: Padua; PR: Parma; PV: Pavia; RA: Ravenna; RE: Reggio Emilia; RI: Rimini; RO: Rovigo; SO: Sondrio; SP: La Spezia; SV: Savona; TN: Trento; TO: Turin; TV: Treviso; VA: Varese; VB: Verbania; VC: Vercelli; VE: Venice; VI: Vicenza; VR: Verona

on the capital of each province. In Fig. 1, the map of the selected provinces and the location of capital cities are reported.

\section{Epidemiological data collection and processing}

The epidemiological evolution of the new SARS-CoV-2 cases was not available at city level. Therefore, the epidemiological data referred to each single province, provided by the Italian National Civil Protection (INCP 2020), were considered. In order to compare the spread rapidity of the CoViD-2019, seeding time (ST) and doubling time (DT) were used. As proposed by Zhou et al. (2020), two authors independently selected the date on which each epidemic curve seemed to rise and, in case of discrepancy, a third author defined which of the two dates to choose. The median of the cumulative cases reported up to the day before the rise of the curve (T1) was called seeding number (SN). The ST was considered equivalent to the time that elapses between the first case identified in each province and reported by official data (T0) and the achievement of a number of cases equal to SN. To quantify the DT, the new cumulative cases from T1 were fitted with exponential curve (Eqs. (1) and (2)):

$$
\begin{aligned}
& I=I_{0}+a_{1} * e^{t / a 2} \\
& \text { DT }[d]=a_{2} * \ln (2)
\end{aligned}
$$

where $I$ represents the number of new infections and $t[d]$ is the progressive number of days (considering $\mathrm{T} 1$ as the first day).

\section{Particulate matter data collection and processing}

Data of $\mathrm{PM}_{10}$ and $\mathrm{PM}_{2.5}$, for all cities, were collected from the local environmental protection agencies (APPA Trento 2020; ARPA Emilia-Romagna 2020; ARPA Liguria 2020; ARPA Lombardia 2020; ARPA Piemonte 2020; ARPA Valle d'Aosta 2020; ARPA Veneto 2020). All air quality control units, located in the capital cities, which measured PM in the selected periods, were used (Table S1) in order to obtain $\mathrm{PM}_{10}$ and $\mathrm{PM}_{2.5}$ concentrations. Forlì and Cesena are co-capitals of their province and were considered as a single city. Data of $\mathrm{PM}_{2.5}$ in Belluno, Ferrara and Reggio Emilia were not available. The daily averages $(24 \mathrm{~h})$ of the air pollutants for each city were calculated with the median, the standard deviation and the confidence interval.

\section{Comparison of the data}

In order to compare air quality data $\left(\mathrm{PM}_{10}\right.$ and $\left.\mathrm{PM}_{2.5}\right)$ with epidemiological data (ST and DT), a statistical analysis was conducted, and the correlation matrices of Pearson and Spearman were identified. Moreover, three different fittings (linear, quadratic and cubic) were used to investigate a correlation between the CoViD-19 spread rapidity in Northern Italy and PM. Finally, the CoViD-19 model, already proposed by Zhou et al. (2020) for the evaluation of the epidemic risk of a given area based on the DT and the ST, was used and the results were compared with the concentration of PM to investigate the possible influence on CoViD-19 spread rapidity.

\section{Determination of periods}

The choice of the periods in which to select the epidemiological and the air quality data has been made considering the average incubation time of the SARS-CoV-2 to evaluate the actual period during which contagion among people could have occurred. Several studies determined that the incubation time could be up to 10-15 d (Backer et al. 2020; Lai et al. 2020; Li et al. 2020). Therefore, the air quality data have been selected anticipating by $15 \mathrm{~d}$ the T0 and ending, as a maximum precautionary limit, in the 8th March 2020 (for the determination of T0, please refer to "Epidemiological analysis"). In the 8th March 2020, several restrictions were imposed in part of Northern Italy, and in 9th March, 2020, they were extended at the rest of the country (DPCM 2020a, b). Following the further increase in the number of infections, the restrictions were made even more severe starting from March 11th, 2020 (DPCM 2020c). In order to study only the exponential tract of the contagion curve, no epidemiological data after the 18th March 2020 were considered (Fig. 2). In some red areas (around the city of Lodi), the restrictions have been imposed earlier than in the rest of the region. The different lockdown timing could have direct repercussions on the epidemiological curve, and therefore in Lodi, the selected period ended in 1 March 2020 (IMH 2020a, 2020b). Also in Bergamo and Lecco, the influence due to lockdown was already visible before the 18th March 2020. In these cases, the selected periods were shortened.

\section{Results and discussion}

\section{Epidemiological analysis}

The official number of infections has been used to determine $\mathrm{T} 0$ and $\mathrm{T} 1$ for each province (Table S2), and fitting the 


\section{$\mathbf{P M}_{10}\left[\mu \mathrm{g} \mathrm{m}^{-3}\right]$}

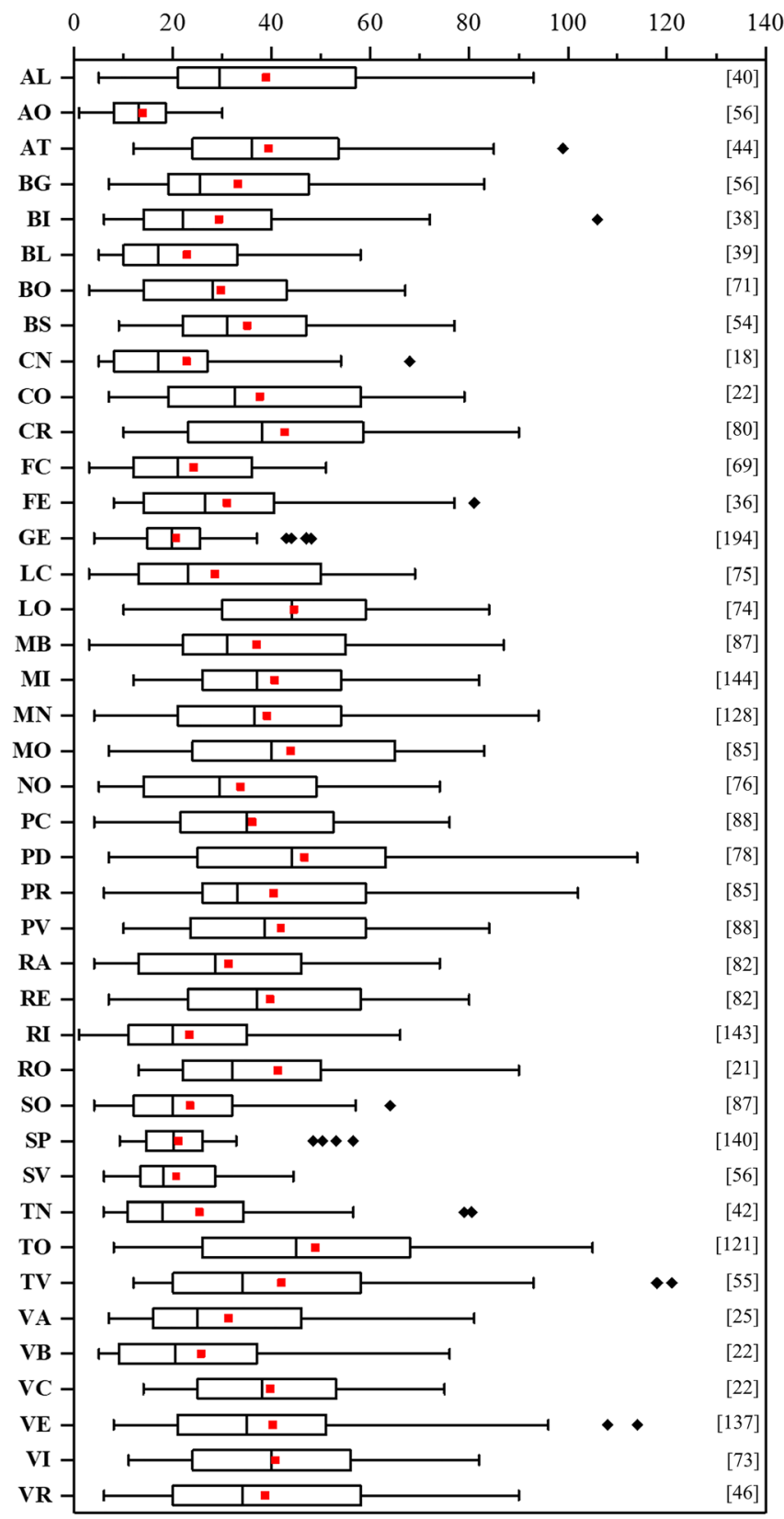

Fig. $4 \mathrm{PM}_{10}$ and $\mathrm{PM}_{2.5}$ concentrations during air quality monitoring period for each city. In brackets, numbers of data are reported. Boxplots represent the distance between the first and third quartiles while whiskers are set as the most extreme (lower and upper) data point not exceeding 1.5 times the quartile range from the median. AL: Alessandria; AO: Aosta; AT: Asti; BG: Bergamo; BI: Biella; BL: Belluno; BO: Bologna; BS: Brescia; $\mathrm{CN}$ : Cuneo; CO: Como; CR: Cremona; FC: Forlì and Cesena;

cumulative number of total infections from $\mathrm{T} 1$ by an exponential curve (Fig. S1 and Tab. S3), the ST and DT have been

\section{$\mathbf{P M}_{25}\left[\mu \mathbf{g ~ m}^{-3}\right]$}

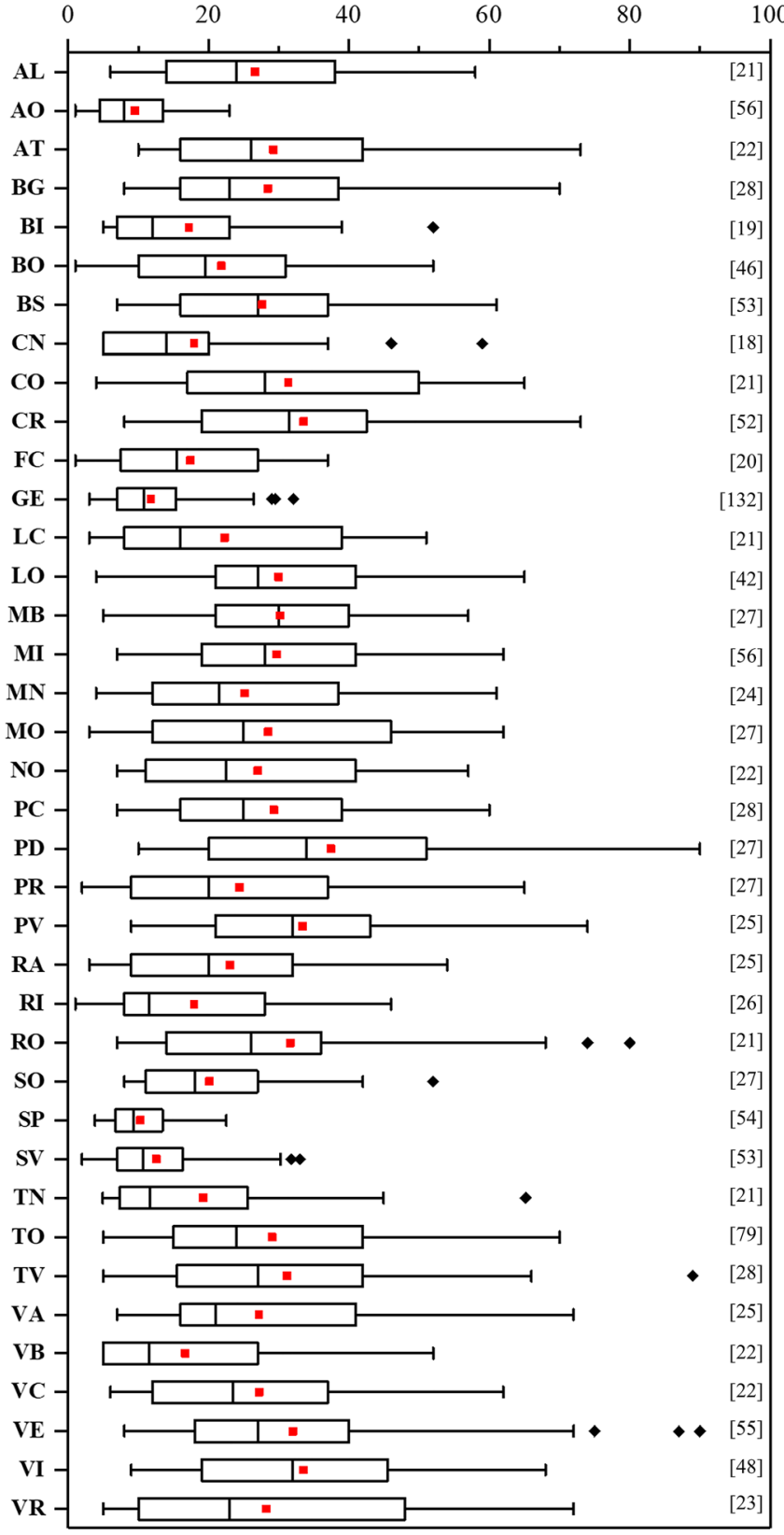

FE: Ferrara; GE: Genoa; LC: Lecco; LO: Lodi; MB: Monza; MI: Milan; MN: Mantova; MO: Modena; NO: Novara; PC: Piacenza; PD: Padua; PR: Parma; PV: Pavia; RA: Ravenna; RE: Reggio Emilia; RI: Rimini; RO: Rovigo; SO: Sondrio; SP: La Spezia; SV: Savona; TN: Trento; TO: Turin; TV: Treviso; VA: Varese; VB: Verbania; VC: Vercelli; VE: Venice; VI: Vicenza; VR: Verona

calculated for each city considered in the study (Fig. 3). These values varied significantly. 
Table 1 Pearson and Spearman correlations for DT, ST, $\mathrm{PM}_{10}$ and $\mathrm{PM}_{2.5}$.

\begin{tabular}{llllll}
\hline & & DT & ST & PM $_{10}$ & PM $_{2.5}$ \\
\hline DT & Pearson & 1 & & & \\
& Spearman & 1 & & & \\
ST & Pearson & $-0.0398^{\mathrm{b}}$ & 1 & & \\
& Spearman & $-0.2307^{\mathrm{a}}$ & 1 & & \\
$\mathrm{PM}_{10}$ & Pearson & $0.0065^{\mathrm{b}}$ & $-0.3887^{\mathrm{a}}$ & 1 & \\
& Spearman & $0.0436^{\mathrm{b}}$ & $-0.3785^{\mathrm{a}}$ & 1 & \\
$\mathrm{PM}_{2.5}$ & Pearson & $0.0646^{\mathrm{b}}$ & $-0.3969^{\mathrm{a}}$ & $0.9122^{\mathrm{b}}$ & 1 \\
& Spearman & $0.2361^{\mathrm{a}}$ & $-0.3990^{\mathrm{a}}$ & $0.8667^{\mathrm{a}}$ & 1 \\
\hline
\end{tabular}

${ }^{\text {a }} p$-value $>0.05$.

${ }^{\mathrm{b}} p$-value $<0.05$

Regarding the ST, the areas that have values equal to 1 , and which a surge in infections has been highlighted right from the start, are those that showed the first clusters of CoViD-19 (mainly south-Lombardy and Padua in Veneto). Other provinces, on the other hand, showed an effective growth of the epidemic curve only several days after the first recorded cases (e.g. 12 days in Sondrio, 11 days in La Spezia, 8 days in Ravenna and 5 days in Como and Varese).

Asti and Savona showed the higher DT, $14.9 \mathrm{~d}$ and 11.4 $\mathrm{d}$, respectively, representing a slower spread of the CoViD19 infection among the population. On the contrary, other cities such as Lodi, Aosta, Novara and Turin were characterised by a DT fewer than $2.5 \mathrm{~d}$. In these cases, the transmission of the virus among the population was faster. As expected, the minor DT (1.2 d) belongs to Lodi which was the first area of contagion and outbreak of the CoViD19 in Italy. The DT obtained in this study is in accordance with other results reported in scientific literature. D'Arienzo and Coniglio (2020) identified DT equals to $3.1 \mathrm{~d}$ for Italy in the period February 25th-March 12th, 2020. In the period February 20th-March 24th, in the Italian regions of Lombardy and Emilia Romagna, Riccardo et al. (2020) evaluated DT equals to $2.7 \mathrm{~d}$. Setti et al. (2020b) highlighted that in Milan, before March 13th, DT was $2.0 \mathrm{~d}$.

\section{Particulate matter}

In Fig. 4, the average and median values of $\mathrm{PM}_{10}$ and $\mathrm{PM}_{2.5}$ in each city for the selected periods are shown. Among the 41 cities, the situation was very heterogeneous. Cremona, Lodi, Milan, Modena, Padua, Parma, Pavia, Rovigo, Turin, Treviso, Venice and Vicenza presented a mean value of $\mathrm{PM}_{10}$ above $40 \mu \mathrm{g} \mathrm{m}^{-3}$ and the highest mean value of $\mathrm{PM}_{10}\left(48.8 \mu \mathrm{g} \mathrm{m}^{-3}\right)$ was reached in Turin. A similar trend was observed for $\mathrm{PM}_{2.5}$, where a concentration higher than $30 \mu \mathrm{g} \mathrm{m}^{-3}$ was found in Cremona, Lodi, Monza, Padua, Pavia, Rovigo, Treviso,
Venice and Vicenza. In this case, Padua showed the highest mean value of $\mathrm{PM}_{2.5}\left(37.4 \mu \mathrm{g} \mathrm{m}^{-3}\right)$. On the contrary, the lowest mean values of $\mathrm{PM}_{10}$ and $\mathrm{PM}_{2.5}$ were detected in Aosta and were equal to $13.8 \mu \mathrm{g} \mathrm{m}^{-3}$ and $9.5 \mu \mathrm{g} \mathrm{m}^{-3}$, respectively. Other areas with the low mean values of $\mathrm{PM}_{10}$ and $\mathrm{PM}_{2.5}$ were the seaside cities of Genoa $\left(20.6 \mu \mathrm{g} \mathrm{m}^{-3}\right.$ and $11.8 \mathrm{\mu g} \mathrm{m}^{-3}$, respectively), Savona $\left(20.6 \mathrm{\mu g} \mathrm{m}^{-3}\right.$ and $12.5 \mathrm{\mu g} \mathrm{m}^{-3}$, respectively) and La Spezia $\left(21.2 \mu \mathrm{g} \mathrm{m}^{-3}\right.$ and $10.3 \mu \mathrm{g} \mathrm{m}^{-3}$, respectively), also in this case probably due to weather conditions, such as wind and precipitation, that could have positively influenced the air quality. In fact, the concentration of atmospheric PM is highly sensitive to weather conditions and factors such as wind and precipitation can strongly influence its concentration in the air (Baklanov et al. 2016; Collivignarelli et al. 2020a).

\section{Statistical analysis and discussion}

To assess a possible dependence between the rapidity of spread of CoViD-19 among the population and the concentration of $\mathrm{PM}_{10}$ and $\mathrm{PM}_{2.5}$, air quality and epidemiological data were analysed and Pearson and Spearman correlations were calculated (Table 1). The results show that Spearman's $R$ is higher for DT-PM 10 and DT-PM $2.5: 0.0436$ and 0.2361 , respectively. Pearson's and Spearman's $R$ are substantially equal for ST-PM 10 and ST-PM 2.5 . Moreover, as confirmed by the literature (Andrée 2020), a very strong positive correlation between $\mathrm{PM}_{10}$ and $\mathrm{PM}_{2.5}$ exists $(R=0.9122$ and 0.8667 with Pearson and Spearman, respectively). It is however evident that the correlation indices between PM and the DT of the number of infected people (inversely proportional to propagation speed of the epidemic) are substantially very low. The results highlighted also low negative values of Pearson and Spearman correlation indices between PM and the ST (also in this case, inversely proportional to the rapidity of CoViD-19 spread). The fact that ST and DT are unrelated to each other (both for Pearson and for Spearman) represent an aspect that highlights how these two parameters are strictly influenced by other aspects, such as sociability and living conditions, resulting from the presence of the coronavirus.

In order to better study the behaviour of ST and DT as a function of $\mathrm{PM}_{10}$ and $\mathrm{PM}_{2.5}$, these values have been fitted with linear, quadratic and cubic functions (Fig. 5). In the ST$\mathrm{PM}_{10}$ case, the function that best approximates the points is that of 3rd degree $\left(R^{2}=0.227\right)$, while in the case of ST-PM 2.5 , all functions return substantially equal $R^{2}(0.158-0.162)$. In the DT-PM 10 and DT-PM 2.5 analysis, the $R^{2}$ remained always nearly to zero. In all cases, two aspects can be highlighted: (i) the 2nd- and 3rd-degree functions do not substantially improve the fitting of the points with respect to the linear function and (ii) the $R^{2}$ values remain decidedly low in order to define the accurate fitting. 

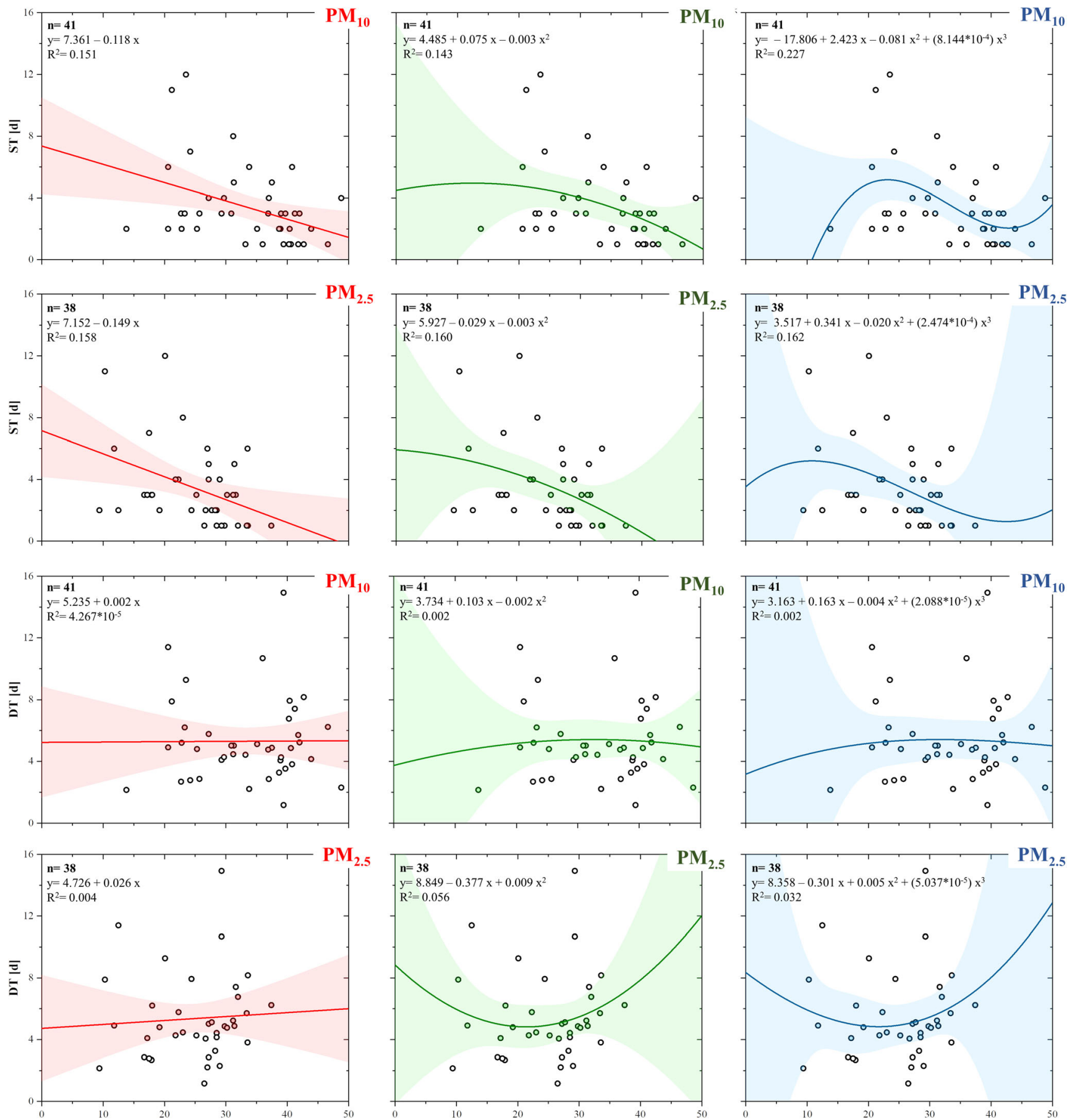

Fig. 5 Fitting of ST and DT with $\mathrm{PM}_{10}$ and $\mathrm{PM}_{2.5}$ with linear (red), parabolic (green) and cubic (blue) functions. The coloured bands represent the 95\% confidence interval. $n$ : number of data

Zhou et al. (2020) proposed a model for the assessment of epidemic risk in different countries of the world determining four risk categories (high risk, moderately high risk, moderately low risk and low risk) based on the values of ST and DT. This model has been applied on the data processed in the current study, and the results were compared with the mean concentration of PM to investigate a possible correlation (Fig. 6).
According to the model of Zhou et al. (2020), the results show that almost all the cities in Northern Italy analysed were in the high, moderately high, and moderately low risk bands in the initial phase of CoViD-19 spread. In the low epidemic risk band, the measured $\mathrm{PM}_{10}$ concentration was slightly lower than in the other bands. However, this last result should be considered partial given the limited sample size $(n=3)$. Comparing the 
Fig. 6 Map of the risk using the ST/DT model proposed by Zhou et al. (2020). $\alpha$ : high risk; $\beta$ : moderately high risk; $\gamma$ : moderately low risk; $\delta$ : low risk a

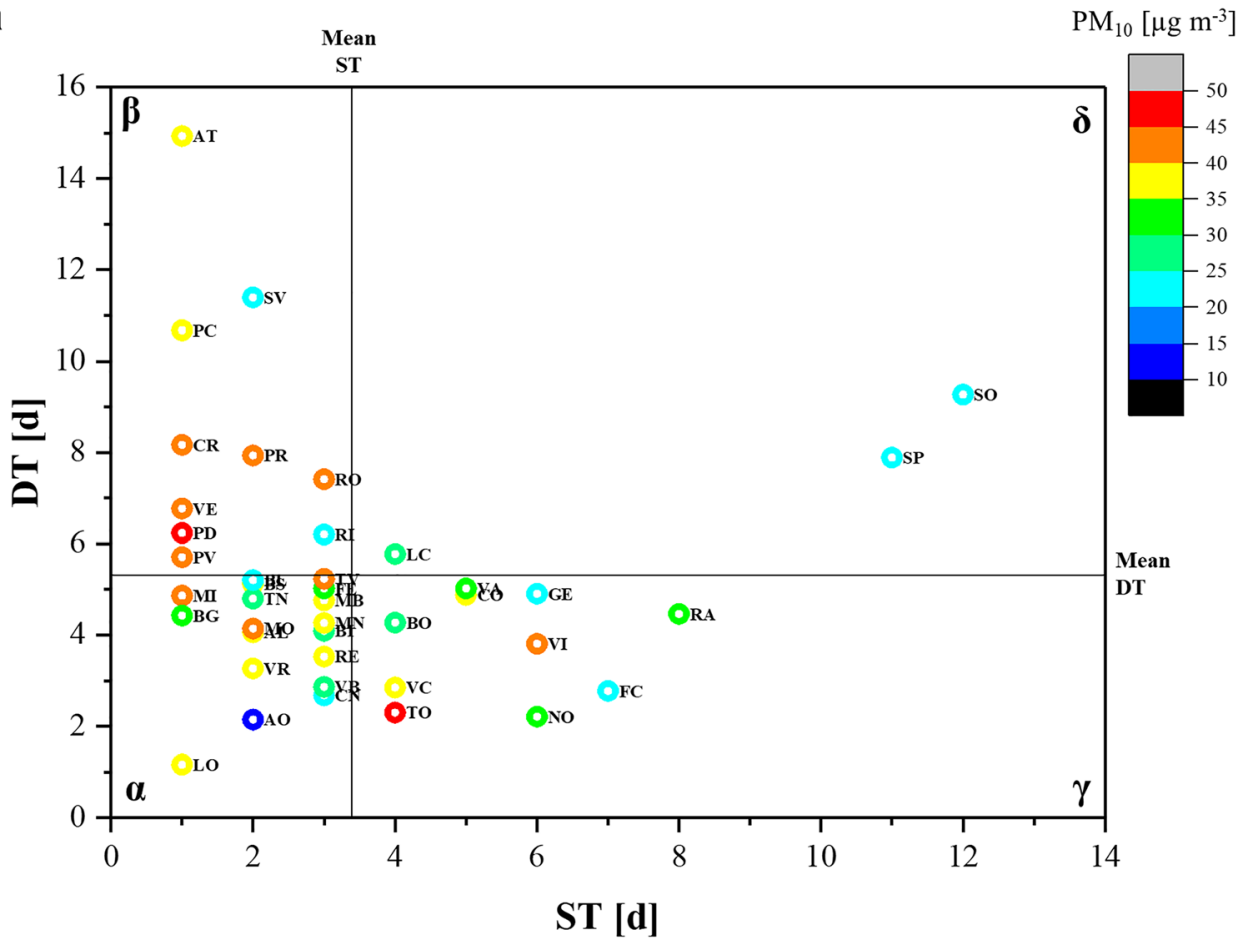

b

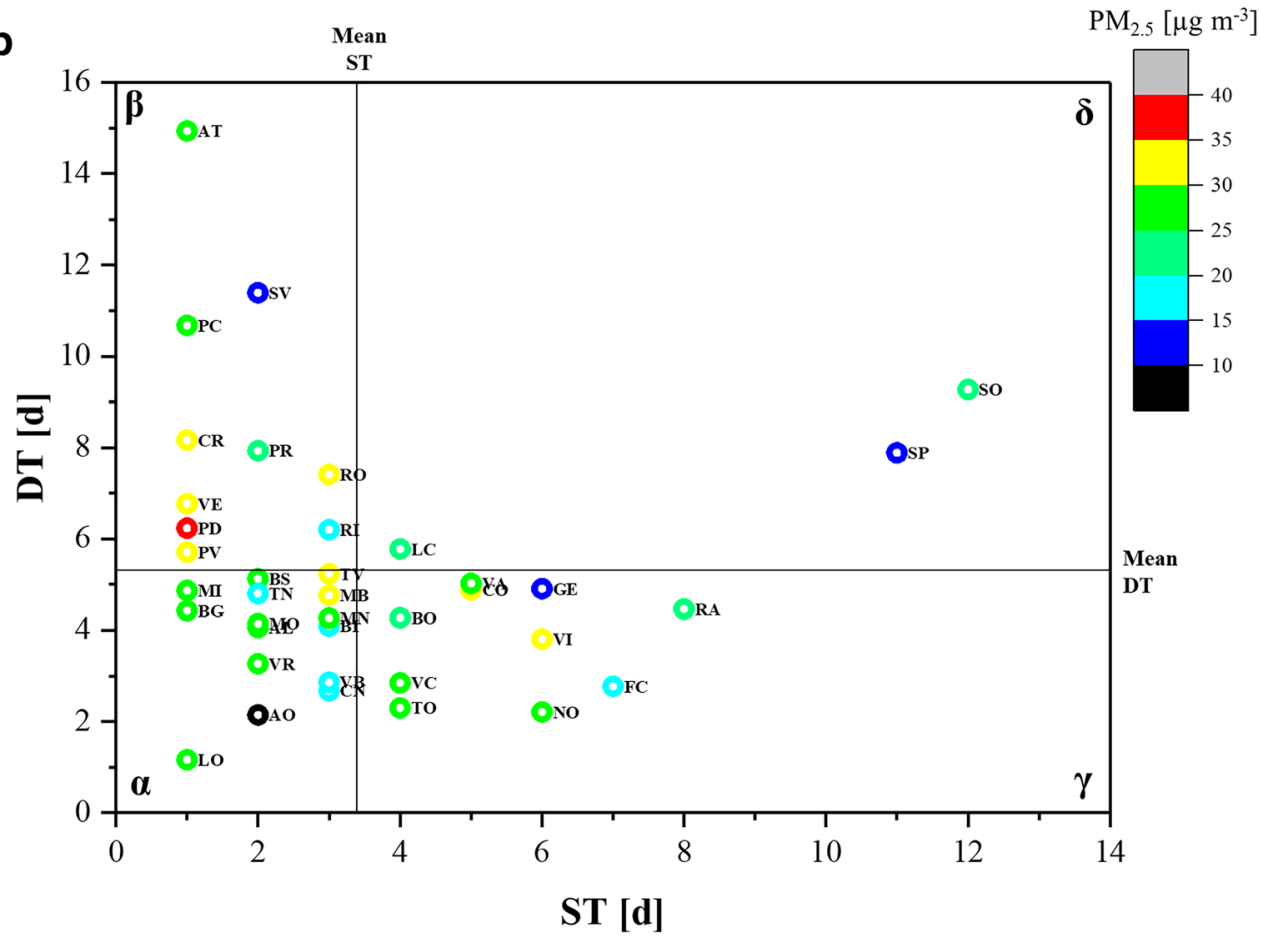

PM concentrations in the cities located in the other bands, no substantial differences were highlighted. For instance, the average concentration of $\mathrm{PM}_{10}$ and $\mathrm{PM}_{2.5}$ in the areas identified at moderately low risk was slightly higher than that measured in the areas considered at high risk (Fig. 7). Therefore, also using the risk model proposed by Zhou et al. (2020), no strong influence of PM on CoViD-19 spread rapidity can be highlighted.

The strength of this study lies in immediacy and practicality. Comparing the epidemiological and air quality data of 41 cities in Northern Italy in the most affected regions from CoViD-19 and taking also into account the possible incubation period of the 
Fig. $7 \mathrm{PM}_{10}$ and $\mathrm{PM}_{2.5}$ concentrations by risk bands. Boxplots represent the distance between the first and third quartiles while whiskers are set as the most extreme (lower and upper) data point not exceeding 1.5 times the quartile range from the median. $n$ : number of data; $\alpha$ : high risk; $\beta$ : moderately high risk; $\gamma$ : moderately low risk; $\delta$ : low risk

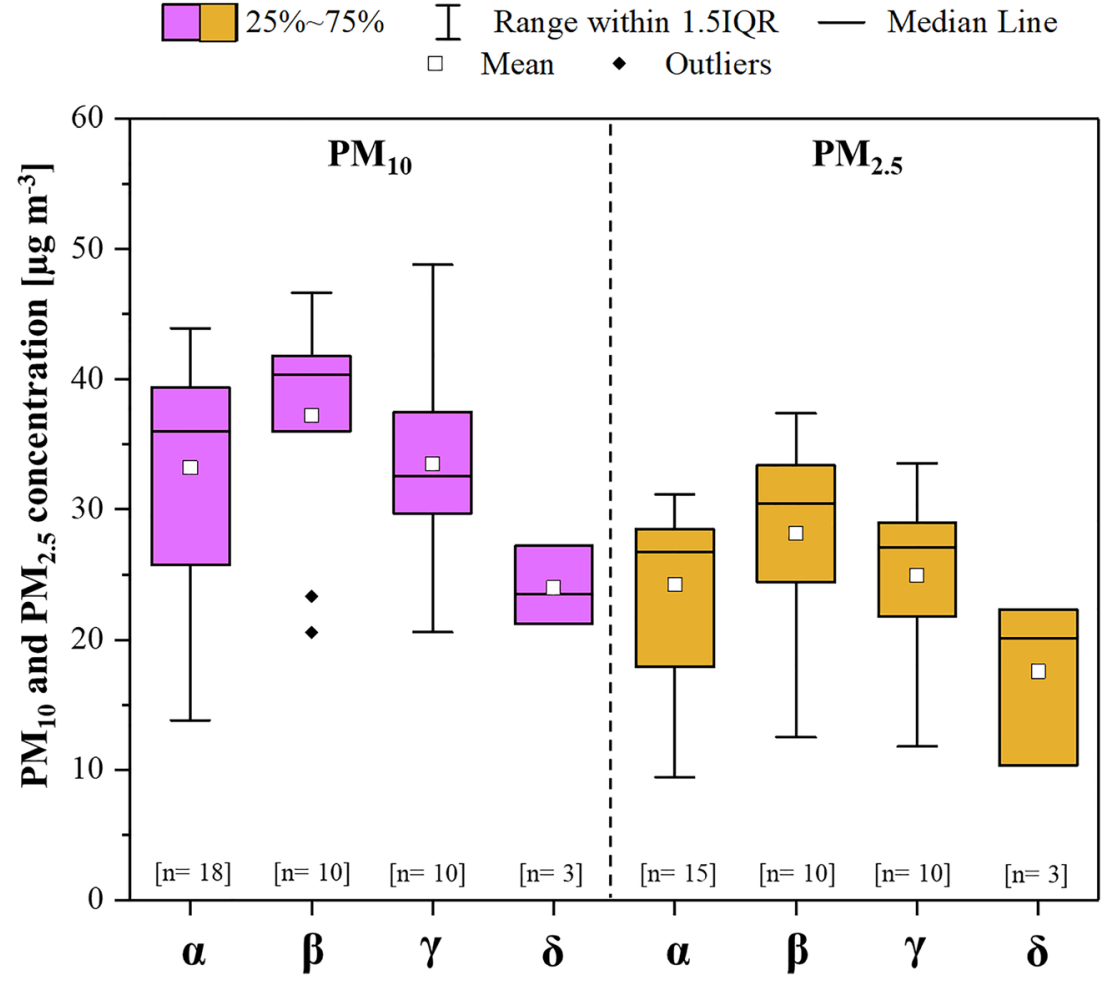

disease, the results allowed excluding that high concentration of PM was the primary cause of the high rapidity of CoViD-19 spread. This agrees with what Belosi et al. (2021) found. By estimating the concentration of SARS-CoV-2 in outdoor air in Lombardy using a box model, they excluded that the presence of high concentrations of PM could act as a vehicle for the infection (Belosi et al. 2021).

However, the opinion of the scientific community on the influence of PM on the infected population rate is conflicting. Other studies obtained positive correlations among the number of infected, mortality, and the concentration of PM in the air (Ma et al. 2020; Zhu et al. 2020). For instance, Setti et al. (2020b) would seem to have obtained an opposite result compared to the present study, highlighting a clear correlation between PM and SARS-CoV-2 infections. However, the results of the present study are only partially comparable with literature (e.g., Setti et al. (2020b)), where in most cases the correlation between $\mathrm{PM}$ and the rate of infected people (cases/population) was assessed, instead of the rapidity of contagion with the use of DT. This difference in result could be attributed to different methodological approaches and also to different scopes. In fact, the present paper aims to evaluate the possible primary role of PM in the rapidity of virus transmission rather than investigating the influence of average daily $\mathrm{PM}_{10}$ exceedances on the rate of infections. Also, Delnevo et al. (2020) observed that a possible statistical correlation between air pollution and CoViD-19 infections, in Emilia-Romagna (Italy), could exist. However, even in this case, the results are only partially comparable with the present study as the new daily infections were used to evaluate the epidemiological situation, instead of the rapidity of contagion intended as DT.

Despite the results of the present study exclude that PM alone was the primary the high CoViD-19 spread rapidity in some areas of Northern Italy, it is becoming increasingly clear, also by following the epidemic trends worldwide, that several other aspects should also be considered. Focusing exclusively on air pollution can lead to spurious associations, because socio-economic and cultural factors often play a concurrent role. Andree (2020) presents a detailed analysis of the Dutch situation, by studying areas, hotspots, pollution loads, social links, habits, age, gender, household composition and lifestyle. In addition, the variability in healthcare systems and identification practises of infected people highly affect the data about pandemic behaviour. Liu et al. (2020) observed that also meteorological factors play a role in the CoViD-19 transmission and SARS-CoV-2 transmission was likely favoured by low temperature, mild diurnal temperature range and low humidity. Therefore, a synergistic action of PM with other factors, e.g., other air pollutants, meteorological conditions and socio-economic aspects, could not be excluded.

\section{Discussion about the possible limitations of the present study}

These results should be considered in the light of some possible limitations. In this study, the Authors did not consider the synergistic action of PM with other factors. As for other viral 
pathogens, high particulate concentration plays a crucial role in weakening the immune system (Glencross et al. 2020). In case of chronic exposure, the atmospheric particulate has proved to indirectly promote the diffusion of SARS-CoV-2, e.g., by enhancing its adhesion to angiotensin-converting enzyme 2 (ACE2) (Comunian et al. 2020; Tung et al. 2021). Together with particulate matter, the long-term exposure to other atmospheric pollutants increases the susceptibility not only to respiratory viral (and bacterial) pathogens but also, exerting a chronic inflammatory stimulus, to cardiovascular and neoplastic diseases (Andersen et al. 2017; Kim et al. 2017; Yang et al. 2019; Conticini et al. 2020; Fattorini and Regoli 2020; Iriti et al. 2020). These represent co-morbidity factors in case of CoViD-19 (Sanyaolu et al. 2020). Indeed, several other authors considered also the parallel contribution of other socio-economic aspects (e.g., density and age of population, mobility of population and healthcare expenditures) (e.g., Andree 2020). However, our goal was assessing the possible primary role of PM in SARS-CoV-2 transmission in Northern Italy, hence in epidemic spread, rather than investigating the severity of cases. In fact, in this study also, the results of swabs of asymptomatic subjects have been counted.

Failure to consider social distancing measures adopted by Italian population independently from Government actions could represent another limitation of this work because this could make difficult to compare the differences in DTs. However, to overcome this aspect focusing on the massive increase occurred before the blockade was imposed, the authors neglected the data (i.e., the number of positive swabs) of the period in which the effects of the lockdown started to be visible.

Moreover, the possibility that a person residing in one province may be infected in another following a travel for work, study or leisure purposes was also not considered and could represent a limitation of the study. Mobility between provinces and regions is an aspect that could be studied in the future by adopting an estimate of the mobility rate despite this being opposed to the immediacy and practicality of the current model.

Finally, the geographical area that the authors chose can appear slightly exiguous knowing that the use of macroscopic statistical models to small territories involves a great variability. In the initial phase of CoViD-19 spread, Italy was almost divided in two parts, being Centre and South all but free from infection nuclei. Therefore, including a broader area, beside North, would have led to inaccuracy. Northern Italy represented a grave and unique reality in Europe, because, there, first, the pandemics burst and grew exponentially. After this heavy onset, the lockdown national restrictions prescribed by the Government prevented the virus from spreading massively also in Central and Southern Italy. This scenery maintained "double" until the end of Italian first wave. Our criterion of data selection proved to be consistent again considering that in Centre and South the growth of the pandemic was detected after lockdown was imposed and therefore affected by the government measures. Northern Italy accounts for $34 \%$ of the Italian land and presents a huge heterogeneity in terms of PM concentration. The precise objective of the present investigation was to focus on the regions where people were heavily hit by the pandemics.

\section{Conclusion}

In this work, considering an incubation time of $10-15 \mathrm{~d}$, data on the concentration of $\mathrm{PM}_{10}$ and $\mathrm{PM}_{2.5}$ were analysed and compared with the rapidity of spread of CoViD-19 (intended as ST and DT) in 41 cities of Northern Italy. This work excludes that PM alone was the primary the high CoViD-19 spread rapidity. Pearson's and Spearman's indices did not highlight any correlation between PM and epidemiological data. Moreover, three different fittings (linear, quadratic and cubic) were used and in all cases of comparison two aspects can be highlighted: (i) the 2nd- and 3rd-degree functions do not substantially improve the fitting of the points with respect to the linear function and (ii) the $R^{2}$ values remain decidedly low in order to define the accurate fitting. A model ST/DT for the evaluation of the epidemic risk, already proposed in literature, was applied but no strong influence of PM has been found. However, the authors do not exclude that a synergistic action with other factors (such as meteorological, socioeconomic and cultural factors) could exist and therefore other studies to further comprehend, for instance, the influence of other atmospheric pollution parameters (e.g., $\mathrm{NO}_{x}$ ), meteorological conditions (e.g., temperature, solar irradiance and humidity), lifestyle and social links on the rapidity of spread of the SARS-CoV-2 are strongly suggested.

Supplementary Information The online version contains supplementary material available at https://doi.org/10.1007/s11356-021-12735-x.

Author contribution Maria Cristina Collivignarelli: Conceptualisation, methodology, supervision, validation, writing

Alessandro Abbà: Methodology, validation, visualisation, writing

Francesca Maria Caccamo: Data curation and formal analysis, writing Giorgio Bertanza: Methodology, validation, writing

Roberta Pedrazzani: Data curation and formal analysis, validation, writing

Marco Baldi: Visualisation, validation

Paola Ricciardi: Visualisation, writing

Marco Carnevale Miino: Conceptualisation, data curation and formal analysis, methodology, supervision, validation, writing

Funding Open access funding provided by Università degli Studi di Pavia within the CRUI-CARE Agreement.

Availability of data and materials All data generated or analysed during this study are included in this published article

Code Availability Not applicable 


\section{Declarations}

Ethical approval Not applicable

Consent to participate Not applicable

Consent to publish Not applicable

Competing interests The authors declare no competing interests.

Open Access This article is licensed under a Creative Commons Attribution 4.0 International License, which permits use, sharing, adaptation, distribution and reproduction in any medium or format, as long as you give appropriate credit to the original author(s) and the source, provide a link to the Creative Commons licence, and indicate if changes were made. The images or other third party material in this article are included in the article's Creative Commons licence, unless indicated otherwise in a credit line to the material. If material is not included in the article's Creative Commons licence and your intended use is not permitted by statutory regulation or exceeds the permitted use, you will need to obtain permission directly from the copyright holder. To view a copy of this licence, visit http://creativecommons.org/licenses/by/4.0/.

\section{References}

Andersen ZJ, Stafoggia M, Weinmayr G et al (2017) Long-term exposure to ambient air pollution and incidence of postmenopausal breast cancer in 15 European cohorts within the ESCAPE Project. Environ Health Perspect 125:107005. https://doi.org/10.1289/ EHP1742

Andrée BPJ (2020) Incidence of Covid-19 and connections with air pollution exposure: evidence from the Netherlands

APPA Trento (2020) Data of air quality in Trentino (in Italian)

ARPA Emilia-Romagna (2020) Data of air quality in Emilia-Romagna (in Italian)

ARPA Liguria (2020) Data of air quality in Liguria Italy (in Italian)

ARPA Lombardia (2020) Data of air quality in Lombardy. https://www. arpalombardia.it/Pages/Aria/Richiesta-Dati.aspx. Accessed 12 Apr 2020

ARPA Piemonte (2020) Data of air quality in Piemonte (in Italian)

ARPA Valle d'Aosta (2020) Data of air quality in Valle D'aosta (in Italian)

ARPA Veneto (2020) Data of air quality in Veneto (in Italian). https:// www.arpa.veneto.it/temi-ambientali/aria. Accessed 25 Apr 2020

Backer JA, Klinkenberg D, Wallinga J (2020) Incubation period of 2019 novel coronavirus $(2019-\mathrm{nCoV})$ infections among travellers from Wuhan, China, 20-28 January 2020. Eurosurveillance 25: 2000062. https://doi.org/10.2807/1560-7917.ES.2020.25.5. 2000062

Baklanov A, Molina LT, Gauss M (2016) Megacities, air quality and climate. Atmos Environ 126:235-249. https://doi.org/10.1016/j. atmosenv.2015.11.059

Belosi F, Conte M, Gianelle V et al (2021) On the concentration of SARS-CoV-2 in outdoor air and the interaction with pre-existing atmospheric particles. Environ Res 193:110603. https://doi.org/10. 1016/j.envres.2020.110603

Coccia M (2020) Factors determining the diffusion of COVID-19 and suggested strategy to prevent future accelerated viral infectivity similar to COVID. Sci Total Environ 729:138474. https://doi.org/10. 1016/j.scitotenv.2020.138474
Coker ES, Cavalli L, Fabrizi E et al (2020) The effects of air pollution on COVID-19 related mortality in Northern Italy. Environ Resour Econ 76:611-634. https://doi.org/10.1007/s10640-020-00486-1

Cole MA, Ozgen C, Strobl E (2020) Air Pollution Exposure and Covid19 in Dutch Municipalities. Environ Resource Econ 76:581-610. https://doi.org/10.1007/s10640-020-00491-4

Collivignarelli MC, Abbà A, Bertanza G et al (2020a) Lockdown for CoViD-2019 in Milan: what are the effects on air quality? Sci Total Environ 732:139280. https://doi.org/10.1016/j.scitotenv. 2020.139280

Collivignarelli MC, Collivignarelli C, Carnevale Miino M et al (2020b) SARS-CoV-2 in sewer systems and connected facilities. Process Saf Environ Prot 143:196-203. https://doi.org/10.1016/j.psep.2020.06. 049

Comunian S, Dongo D, Milani C, Palestini P (2020) Air pollution and COVID-19: the role of particulate matter in the spread and increase of COVID-19's morbidity and mortality. Int J Environ Res Public Health 17:4487. https://doi.org/10.3390/ijerph17124487

Conticini E, Frediani B, Caro D (2020) Can atmospheric pollution be considered a co-factor in extremely high level of SARS-CoV-2 lethality in Northern Italy? Environ Pollut 261:114465. https://doi. org/10.1016/j.envpol.2020.114465

Cruz-Sanchez TM, Haddrell AE, Hackett TL et al (2013) Formation of a stable mimic of ambient particulate matter containing viable infectious respiratory syncytial virus and its dry-deposition directly onto cell cultures. Anal Chem 85:898-906. https://doi.org/10.1021/ ac302174y

D'Arienzo M, Coniglio A (2020) Assessment of the SARS-CoV-2 basic reproduction number, R0, based on the early phase of COVID-19 outbreak in Italy. Biosaf Health 2(2):57-59. 3-5. https://doi.org/10. 1016/j.bsheal.2020.03.004

Delnevo G, Mirri S, Roccetti M (2020) Particulate matter and COVID-19 disease diffusion in Emilia-Romagna (Italy). already a cold case? Computation 8:59. https://doi.org/10.3390/computation8020059

DPCM (2020a) Decree of the President of the Council of Ministers of the Italian Republic of March 8, 2020 - Further implementing provisions of the decree-law of 23 February 2020, n. 6, containing urgent measures regarding the containment and management of the epidemiological emergency from COVID-19. President of the Council of Ministers of the Italian Republic, Rome, Italy

DPCM (2020b) Decree of the President of the Council of Ministers of the Italian Republic of March 9, 2020 - Further implementing provisions of the decree-law of 23 February 2020 , n. 6, containing urgent measures regarding the containment and management of the epidemiological emergency from COVID-19. President of the Council of Ministers of the Italian Republic, Rome, Italy

DPCM (2020c) Decree of the President of the Council of Ministers of the Italian Republic of March 11, 2020 - Further implementing provisions of the decree-law of 23 February 2020, n. 6, containing urgent measures regarding the containment and management of the epidemiological emergency from COVID-19. President of the Council of Ministers of the Italian Republic, Rome, Italy

EEA (2017) Air quality in Europe - 2017 report. Copenhagen

EEA (2018) Air quality in Europe - 2018 report. Copenhagen

EEA (2019) Air quality in Europe - 2019 report. Copenhagen

Fattorini D, Regoli F (2020) Role of the chronic air pollution levels in the Covid-19 outbreak risk in Italy. Environ Pollut 264:114732. https:// doi.org/10.1016/j.envpol.2020.114732

Glencross DA, Ho T-R, Camiña N et al (2020) Air pollution and its effects on the immune system. Free Radic Biol Med 151:56-68. https://doi.org/10.1016/j.freeradbiomed.2020.01.179

Horne BD, Joy EA, Hofmann MG et al (2018) Short-term elevation of fine particulate matter air pollution and acute lower respiratory infection. Am J Respir Crit Care Med 198:759-766. https://doi.org/ 10.1164/rccm.201709-1883OC 
IMH (2020a) Ordinance February, 232020 - Urgent measures for the containment and management of the epidemiological emergency from COVID-19. Lombardy region (In Italian). Italian Ministry of Health, Milan, Rome

IMH (2020b) Ordinance February 21, 2020. Italian Ministry of Health, Milan

INCP (2020) Department of Civil Protection COVID-19 in Italy - monitoring of the situation. In: Ital. Natl. Civ. Prot. http://opendatadpc. maps.arcgis.com/apps/opsdashboard/index.html\#/ b0c68bce2cce478eaac82fe38d4138b1. Accessed 10 May 2020

Ionescu G, Apostol T, Rada EC et al (2013) Critical analysis of strategies for PM reduction in urban areas. UPB Sci Bull Ser D Mech Eng 75: $175-186$

Iriti M, Piscitelli P, Missoni E, Miani A (2020) Air pollution and health: the need for a medical reading of environmental monitoring data. Int J Environ Res Public Health 17:2174. https://doi.org/10.3390/ ijerph17072174

Isphording IE, Pestel N (2020) Pandemic meets pollution: poor air quality increases deaths by COVID-19. Bonn, Germany

ISTAT (2020a) Surfaces of statistical administrative units - the surface of Italian Municipalities, Provinces and Regions in 9 October 2011. https://www.istat.it/it/archivio/82599. Accessed 30 May 2020

ISTAT (2020b) Resident population in Italy on 1st January. http:/dati. istat.it/Index.aspx?DataSetCode=DCIS_POPRES1. Accessed 30 May 2020

Kim H, Kim J, Kim S et al (2017) Cardiovascular effects of long-term exposure to air pollution: a population-based study with 900845 person-years of follow-up. J Am Heart Assoc 6:e007170. https://doi. org/10.1161/JAHA.117.007170

Lai C-C, Liu YH, Wang C-Y et al (2020) Asymptomatic carrier state, acute respiratory disease, and pneumonia due to severe acute respiratory syndrome coronavirus 2 (SARS-CoV-2): facts and myths. J Microbiol Immunol Infect 53:404-412. https://doi.org/10.1016/j. jmii.2020.02.012

Li Q, Guan X, Wu P et al (2020) Early transmission dynamics in Wuhan, China, of novel coronavirus-infected pneumonia. N Engl J Med 382:1199-1207. https://doi.org/10.1056/NEJMoa2001316

Liu J, Zhou J, Yao J et al (2020) Impact of meteorological factors on the COVID-19 transmission: a multi-city study in China. Sci Total Environ 726:138513. https://doi.org/10.1016/j.scitotenv.2020. 138513

Ma Y, Zhao Y, Liu J et al (2020) Effects of temperature variation and humidity on the death of COVID-19 in Wuhan, China. Sci Total Environ 724:138226. https://doi.org/10.1016/j.scitotenv.2020. 138226

Masiol M, Benetello F, Harrison RM et al (2015) Spatial, seasonal trends and transboundary transport of PM2.5 inorganic ions in the Veneto region (Northeastern Italy). Atmos Environ 117:19-31. https://doi. org/10.1016/j.atmosenv.2015.06.044

Ogen Y (2020) Assessing nitrogen dioxide $\left(\mathrm{NO}_{2}\right)$ levels as a contributing factor to coronavirus (COVID-19) fatality. Sci Total Environ 726: 138605. https://doi.org/10.1016/j.scitotenv.2020.138605

Perone G (2021) The determinants of COVID-19 case fatality rate (CFR) in the Italian regions and provinces: an analysis of environmental, demographic, and healthcare factors. Sci Total Environ 755:142523. https://doi.org/10.1016/j.scitotenv.2020.142523

QGIS (2020) QGIS Development Team. QGIS geographic information system. Open Source Geospatial Foundation Project.

Riccardo F, Ajelli M, Andrianou XD et al (2020) Epidemiological characteristics of COVID-19 cases in Italy and estimates of the reproductive numbers one month into the epidemic. medRxiv. https://doi. org/10.1101/2020.04.08.20056861
Sanità di Toppi L, Sanità di Toppi L, Bellini E (2020) Novel coronavirus: how atmospheric particulate affects our environment and health. Challenges 11:6. https://doi.org/10.3390/challe11010006

Sanyaolu A, Okorie C, Marinkovic A et al (2020) Comorbidity and its impact on patients with COVID-19. SN Compr Clin Med 2:10691076. https://doi.org/10.1007/s42399-020-00363-4

Setti L, Passarini F, De Gennaro G et al (2020a) SARS-Cov-2RNA found on particulate matter of Bergamo in Northern Italy: first evidence. Environ Res 109754. https://doi.org/10.1016/j.envres.2020.109754

Setti L, Passarini F, De Gennaro G et al (2020b) Potential role of particulate matter in the spreading of COVID-19 in Northern Italy: first observational study based on initial epidemic diffusion. BMJ Open 10:e39338. https://doi.org/10.1136/bmjopen-2020-039338

SIMA (2020) Position paper - evaluation of the potential relationship between particulate matter (PM) pollution and COVID-19 infection spread in Italy

Tateo F, Grassivaro F, Ermani M et al (2019) PM2.5 levels strongly associate with multiple sclerosis prevalence in the Province of Padua, Veneto Region, North-East Italy. Mult Scler J 25:17191727. https://doi.org/10.1177/1352458518803273

Torretta V, Raboni M, Copelli S et al (2013) Application of strategies for particulate matter reduction in urban areas: an Italian case. UPB Sci Bull Ser D Mech Eng 75:221-228

Tung NT, Cheng P-C, Chi K-H et al (2021) Particulate matter and SARSCoV-2: a possible model of COVID-19 transmission. Sci Total Environ 750:141532. https://doi.org/10.1016/j.scitotenv.2020. 141532

Wu X, Nethery RC, Sabath MB et al (2020a) Air pollution and COVID19 mortality in the United States: strengths and limitations of an ecological regression analysis. Sci Adv 6:eabd4049. https://doi. org/10.1126/sciadv.abd4049

Wu X, Nethery RC, Sabath MB, et al (2020b) Exposure to air pollution and COVID-19 mortality in the United States: a nationwide crosssectional study. MedRxiv 1-36. https://doi.org/10.1101/2020.04.05. 20054502

Xu Q, Li X, Wang S et al (2016) Fine particulate air pollution and hospital emergency room visits for respiratory disease in urban areas in Beijing, China, in 2013. PLoS One 11:1-17. https://doi.org/10. 1371/journal.pone.0153099

Yang B-Y, Guo Y, Markevych I et al (2019) Association of long-term exposure to ambient air pollutants with risk factors for cardiovascular disease in China. JAMA Netw Open 2:e190318. https://doi.org/ 10.1001/jamanetworkopen.2019.0318

Yari S, Moshammer H (2020) The effect of ambient air pollution on severity of COVID19: hospitalisation and death. Asian Pacific J Environ Cancer 3:15-16. https://doi.org/10.31557/apjec.2020.3.1. $15-16$

Zhou M, He G, Fan M et al (2015) Smog episodes, fine particulate pollution and mortality in China. Environ Res 136:396-404. https://doi.org/10.1016/j.envres.2014.09.038

Zhou L, Liu J-M, Dong X-P et al (2020) COVID-19 seeding time and doubling time model: an early epidemic risk assessment tool. Infect Dis Poverty 9:76. https://doi.org/10.1186/s40249-020-00685-4

Zhu Y, Xie J, Huang F, Cao L (2020) Association between short-term exposure to air pollution and COVID-19 infection: evidence from China. Sci Total Environ 727:138704. https://doi.org/10.1016/j. scitotenv.2020.138704

Publisher's note Springer Nature remains neutral with regard to jurisdictional claims in published maps and institutional affiliations. 